\title{
Desempenho agronômico de alface americana fertilizada com torta de filtro em ambiente protegido
}

\author{
Adalberto Santi ${ }^{1,2}$; Walcylene LMP Scaramuzza ${ }^{2}$; Alexandro Neuhaus ${ }^{1}$; Rivanildo Dallacort ${ }^{1}$; Willian \\ Krause $^{1}$; Rafael Cesar Tieppo ${ }^{1}$ \\ 'UNEMAT, Depto. Agronomia, Campus Tangará da Serra, C. Postal 379, 78300-000 Tangará da Serra-MT; adalbertosanti@unemat. \\ br; neuhauscba@hotmail.com; rdallacort@gmail.com; krause@unemat.br; rafaeltieppo@yahoo.com.br; ${ }^{2}$ UFMT-FAMEV, Progr. pós- \\ graduação Lato Sensu (em italico) em Agricultura Tropical; walcylene@ufmt.br
}

\section{RESUMO}

Este trabalho foi realizado na Universidade do Estado de Mato Grosso, Campus universitário de Tangará da Serra, com objetivo de avaliar as características agronômicas de cultivares de alface americana mediante doses de torta de filtro, em ambiente protegido. Foi utilizado delineamento experimental de blocos casualizados, em arranjo fatorial de $3 \times 4$, constituído por três cultivares (Júlia, Tainá e Rafaela) e quatro doses $\left(0,10,20\right.$ e 40 t ha $\left.^{-1}\right)$, com quatro repetições. $\mathrm{O}$ tamanho das parcelas foi de $1,2 \times 1,2 \mathrm{~m}$ com 16 plantas e espaçamento $30 \times 30 \mathrm{~cm}$, onde foram analisadas quatro plantas centrais de cada parcela. Foram avaliadas a massa fresca total, massa fresca comercial, massa fresca da cabeça, número de folhas totais, número de folhas comerciais, comprimento do caule, diâmetro do caule, diâmetro da planta. A cultivar Rafaela apresentou desempenho superior para massa fresca total, comercial e da cabeça, na dose de $20 \mathrm{t} \mathrm{ha}^{-1}$ de torta de filtro. As cultivares Júlia e Rafaela expressaram maior diâmetro de planta, diâmetro de caule, número de folhas totais e número de folhas comerciais do que a cultivar Tainá, independente da dose aplicada. A aplicação de torta de filtro proporcionou melhoria no crescimento e qualidade comercial da alface americana.

Palavras-chave: Lactuca sativa, resíduos orgânicos, adubo orgânico, cultivares.

\begin{abstract}
Agronomic performance of crisphead lettuce fertilized with filter cake in protected environment

This work was carried out at the Mato Grosso State University, Tangará da Serra campus, Brazil, aiming to evaluate the agronomic characteristics of crisphead lettuce cultivars depending on filter cake rates application in protected environment. We used a randomized blocks design in a $3 \times 4$ factorial scheme, composed by three cultivars (Júlia, Tainá and Rafaela) and four rates $\left(0,10,20\right.$ and $\left.40 \mathrm{t} \mathrm{ha}^{-1}\right)$, with four replications. Plots size was $1.2 \times 1.2 \mathrm{~m}$ with 16 plants spaced $30 \times 30 \mathrm{~cm}$ each, among which the 4 central plants were evaluated. We assessed the total fresh mass, marketable fresh mass, head fresh mass, total leaf number, marketable leaf number, stem length, stem diameter and plant diameter. The cultivar Rafaela presented the highest performance for fresh mass total, marketable and head, at the filter cake rate of $20 \mathrm{t} \mathrm{ha}^{-1}$. The cultivars Júlia and Rafaela had greater plant diameter, stem diameter, total leaf number and marketable leaf number than cultivar Tainá, regardless the filter cake rate applied. The filter cake application provided higher yield and marketable quality for crisphead lettuce.
\end{abstract}

Keywords: Lactuca sativa, organic residue, organic fertilizer, cultivars.

\section{(Recebido para publicação em 27 de abril de 2012; aceito em 22 de março de 2013) (Received on April 27, 2012; accepted on March 22, 2013)}

\begin{abstract}
A alface, dentre as hortaliças folhosas, é a mais comercializada no Brasil. Apresenta elevado teor de vitaminas e possui grande quantidade de sais minerais. É originária de clima ameno, seu cultivo é próprio para o inverno, atingindo nesse período as maiores produções. Devido ao crescente aumento no consumo dessa hortaliça, faz-se necessário o aumento na quantidade e qualidade do produto. Porém, a qualidade final de um produto agrícola é resultado de diversos fatores, dentre estes da dose de nutrientes (Bernardi et al., 2005).

Entre os tipos de alface cultivados, atualmente, tem-se destacado a alface americana. Esse destaque se deve, principalmente, às características apresenta-
\end{abstract}

das por esse grupo. A alface americana diferencia-se dos demais grupos por apresentar folhas externas de coloração verde-escura, folhas internas de coloração amarela ou branca, imbricadas e crocantes assemelhando-se ao repolho (Yuri et al., 2002).

O cultivo comercial de hortaliças em ambiente protegido é uma atividade consolidada e crescente, principalmente nas proximidades de grandes centros urbano, onde a capacidade de produção intensiva em pequenas áreas atende a grande demanda que estes locais apresentam, tanto em quantidade como em qualidade de produtos hortigranjeiros (Araújo et al., 2010). Segundo Rodrigues et al. (1997), a principal vantagem desta técnica consiste na possibilidade de produção, principalmente de hortaliças, nos períodos de entressafras, permitindo maior regularização da oferta e melhor qualidade dos produtos.

Com o processo de modernização da agricultura houve uma desvalorização dos processos naturais e biológicos, priorizando, principalmente, o uso de adubos minerais de alta solubilidade. O emprego de fertilizantes minerais na cultura da alface é uma prática agrícola que traz resultados satisfatórios em termos de produtividade. Contudo, deve-se levar em consideração a qualidade final do produto, pois sabe-se que seu uso desordenado pode prejudicar a saúde dos consumidores, através da contaminação do lençol freático, além de onerar os custos de produção (Souza \& Resende, 
2006; Silva et al., 2010).

A alface é uma das hortaliças mais cultivadas em pequenas propriedades rurais. Entre os agricultores de baixa renda o seu cultivo, muitas vezes, é feito sem o uso ou com a aplicação de doses muito baixas de adubo orgânico o que, geralmente, proporciona baixas produtividades de biomassa, especialmente em solos ácidos e pobres em nutrientes (Inocêncio et al., 2009). A utilização de compostos orgânicos em substituição ou complementação à adubação mineral, ganha cada vez mais importância sob o ponto de vista econômico, da conservação das propriedades físicas e químicas do solo e da redução do uso de adubos minerais (Penteado, 2000; Bulluck et al., 2002; Filgueira, 2008).

$\mathrm{O}$ aproveitamento de resíduos da agroindústria como componente de adubos orgânicos pode garantir a obtenção de um material alternativo, de baixo custo, de fácil disponibilidade e auxiliar na redução do seu acúmulo no ambiente (Lima et al., 2007). Uma das alternativas de adubação suplementar orgânica em hortaliças seria o uso da torta de filtro, que é um subproduto da indústria canavieira, proveniente da purificação do caldo sulfitado e de baixíssimo custo, onde são gerados, em média, a cada $1.000 \mathrm{~kg}$ de cana de açúcar moída, $30 \mathrm{~kg}$ de torta de filtro (Casarin et al., 1989).

Apesar da extrema importância que a adubação representa para o cultivo da alface, ainda são escassos os trabalhos no Brasil, que avaliam a adubação com fertilizantes orgânicos sobre a produção de alface em cultivo protegido. $\mathrm{O}$ conhecimento de fatores relacionados à composição dos materiais orgânicos utilizados implica, em economia de adubos e obtenção de hortaliças de melhor qualidade.

Objetivou-se avaliar o efeito de doses de torta de filtro nas características agronômicas de cultivares de alface americana, em ambiente protegido, no município de Tangará da Serra-MT.

\section{MATERIAL E MÉTODOS}

O experimento foi realizado em área experimental da Universidade do
Estado de Mato Grosso (UNEMAT), Campus Universitário de Tangará da Serra (14³7'10''S; 57²9'09'O; 320 $\mathrm{m}$ de altitude), de junho a setembro de 2009, em solo classificado como Latossolo Vermelho distroférrico, textura argilosa e relevo suavemente ondulado (Embrapa, 2006). O clima da região é caracterizado por índices pluviométricos de precipitação média anual de $1.800 \mathrm{~mm}$ e temperatura média anual de $24,4^{\circ} \mathrm{C}$. O solo do experimento apresenta as características químicas: $\mathrm{pH}$ em $\mathrm{CaCl}_{2}=4,7 ; \mathrm{MO}=41 \mathrm{~g} \mathrm{dm}^{-3} ; \mathrm{P}($ resina $)=$ $6 \mathrm{mg} \mathrm{dm}^{-3} ; \mathrm{K}^{+}=0,8 \mathrm{mmol}_{\mathrm{c}} \mathrm{dm}^{-3} ; \mathrm{Ca}^{2+}=$ $14 \mathrm{mmol}_{\mathrm{c}} \mathrm{dm}^{-3} ; \mathrm{Mg}^{2+}=7 \mathrm{mmol}_{\mathrm{c}} \mathrm{dm}^{-3}$; $\mathrm{H}^{+}+\mathrm{Al}^{3+}=46 \mathrm{mmol}_{\mathrm{c}} \mathrm{dm}^{-3} ; \mathrm{Al}^{3+}=2 \mathrm{mmol}_{\mathrm{c}}$ $\mathrm{dm}^{-3} ; \mathrm{S}=16 \mathrm{mg} \mathrm{dm}^{-3} ; \mathrm{B}=0,22 \mathrm{mg} \mathrm{dm}^{-3}$; $\mathrm{Fe}^{2+}=19,8 \mathrm{mg} \mathrm{dm}{ }^{-3} ; \mathrm{Mn}^{2+}=11,3 \mathrm{mg}$ $\mathrm{dm}^{-3} ; \mathrm{Cu}^{2+}=2,3 \mathrm{mg} \mathrm{dm}{ }^{-3} ; \mathrm{Zn}^{2+}=0,1 \mathrm{mg}$ $\mathrm{dm}^{-3}$ e a seguinte composição textural: argila $=561 \mathrm{~g} \mathrm{~kg}^{-1}$; silte $=183 \mathrm{~g} \mathrm{~kg}^{-1} \mathrm{e}$ areia $=256 \mathrm{~g} \mathrm{~kg}^{-1}$.

$O$ cultivo da alface foi realizado em ambiente protegido, modelo túnel alto, com $21 \mathrm{~m}$ de comprimento, 5,20 $\mathrm{m}$ de largura, que possui $2,30 \mathrm{~m}$ de pé-direito e é coberta com película de polietileno transparente de baixa densidade aditivada anti UV de $100 \mu \mathrm{m}$ de espessura.

$\mathrm{O}$ delineamento experimental utilizado foi de blocos casualizados em arranjo fatorial (3x4), constituídos pela combinação de três cultivares de alface americana (Júlia, Tainá, e Rafaela) e quatro doses de torta de filtro $(0,10$, 20, $40 \mathrm{tha}^{-1}$ ), com quatro repetições. A composição química da torta de filtro determinada pelos métodos descritos por Abreu et al. (2009), apresentou na matéria seca: carbono orgânico $=7,9 \%$; $\mathrm{N}=4,8 \% ; \mathrm{P}_{2} \mathrm{O}_{5}=1,76 \% ; \mathrm{K}_{2} \mathrm{O}=0,35 \%$; $\mathrm{Ca}^{2+}=1,61 \% ; \mathrm{Mg}^{2+}=0,45 \%, \mathrm{~S}=0,31 \%$; $\mathrm{Zn}^{2+}=140 \mathrm{mg} \mathrm{kg}{ }^{-1} ; \mathrm{Cu}^{2+}=43 \mathrm{mg} \mathrm{kg}^{-1}$; $\mathrm{Mn}^{2+}=518 \mathrm{mg} \mathrm{kg}^{-1} ; \mathrm{B}=256 \mathrm{mg} \mathrm{kg}^{-1} \mathrm{e}$ $\mathrm{Fe}^{2+}=20.545 \mathrm{mg} \mathrm{kg}^{-1}$.

As adubações químicas básicas, bem como a correção do solo foram realizadas de acordo com as características químicas do solo, segundo Fontes (1999) e Filgueira (2008). Foram aplicados um total de $150 \mathrm{~kg} \mathrm{ha}^{-1}$ de nitrogênio (N), $300 \mathrm{~kg} \mathrm{ha}^{-1}$ de $\mathrm{P}_{2} \mathrm{O}_{5}$ e $90 \mathrm{~kg} \mathrm{ha}^{-1} \mathrm{de}$ $\mathrm{K}_{2} \mathrm{O}$, sendo no plantio aplicado todo o fósforo $(\mathrm{P})$ e $20 \%$ do $\mathrm{N}$ e potássio $(\mathrm{K})$. $\mathrm{O}$ restante do $\mathrm{N}$ e $\mathrm{K}$ foram divididos em três parcelas aos 15, 30 e 45 dias após o plantio. Para fornecimento de N, P e $\mathrm{K}$ foram utilizados: uréia, superfosfato simples e cloreto de potássio, respectivamente.

As mudas foram produzidas em bandejas de poliestireno, sendo o transplantio feito 28 dias após a semeadura, quando as mesmas atingiram quatro folhas definitivas. As dimensões das parcelas utilizadas foram de $1,2 \times 1,2$ $\mathrm{m}$, com 16 plantas no espaçamento de $30 \times 30 \mathrm{~cm}$, e foram analisadas quatro plantas centrais de cada parcela, aos 80 dias após a semeadura.

Foram avaliadas as variáveis: matéria fresca total, matéria fresca comercial, matéria fresca da cabeça, diâmetro da planta, comprimento e diâmetro do caule e contagem do número total e comercial de folhas.

Para a determinação da matéria fresca total, as plantas foram cortadas rente ao solo e medidas suas massas em balança analítica, através da pesagem do número total de folhas de cada planta analisada. A matéria fresca comercial correspondeu à estimativa da matéria, sem a presença das folhas com danos que prejudicassem visualmente a comercialização da planta. A matéria fresca da cabeça foi obtida através da eliminação das folhas que não formaram a cabeça e da determinação das medidas de suas matérias, em balança analítica, com a pesagem apenas da cabeça repolhuda.

O diâmetro da planta foi mensurado através de régua de uma extremidade a outra da planta correspondendo ao diâmetro de uma circunferência. O comprimento e diâmetro do caule foram obtidos através da retirada de todas as folhas das plantas avaliadas, as quais foram medidas posteriormente através da utilização do paquímetro; na determinação do diâmetro do caule, foram tomadas duas medidas aproximadamente perpendiculares na base do caule avaliado. A determinação do número total de folhas foi expressa pelo número total de folhas obtido por contagem direta, enquanto o número comercial de folhas foi obtido através da contagem direta de folhas sem danos visuais.

Os dados obtidos foram submetidos à análise de variância, sendo as médias do fator cultivar comparadas pelo teste de agrupamento Scott-Knott (1974) e, 
as do fator dose de torta de filtro por análise de regressão. Para análise destes dados foi utilizado o programa SISVAR 5.1 (Ferreira, 2008).

\section{RESULTADOS E DISCUSSÃO}

Houve interação significativa entre doses e cultivares na massa fresca total, massa fresca comercial e massa fresca da cabeça. As massas frescas total e da cabeça produzidas pela cultivar Rafaela, foram significativamente superiores às obtidas pelas demais cultivares na, dose $20 \mathrm{t} \mathrm{ha}^{-1}$ de torta de filtro (Tabela 1). Apresentou comportamento quadrático, onde verificou-se uma máxima produção de massa fresca total e massa fresca da cabeça $(533,1 \mathrm{~g})$ na dose 26,7 t ha-1, (354,9 g) com a dose 26,5 t ha ${ }^{-1}$ respectivamente (Figura $1 \mathrm{~A} \mathrm{e} 1 \mathrm{C}$ ). Para a cultivar Júlia não foi possível ajustar equação quadrática, bem como linear (Figura 1A, 1B e 1C). Tanto na cultivar Tainá quanto na Rafaela houve incrementos na produção com a aplicação de torta de filtro.

Para a indústria, alface americana com elevada massa de cabeça comercial é desejável, pois está diretamente relacionada com o rendimento no momento do processamento (Yuri et al., 2004).

Resultados superiores foram obtidos por Yuri et al. (2004) que, utilizando diferentes doses de composto orgânico $\left(0,20,40,60,80 \mathrm{t} \mathrm{ha}^{-1}\right)$ produzido através de camadas alternadas de casca do grão de café, esterco de curral e palha triturada de Crotalaria sp., alcançaram a produtividade máxima de 914,2 g planta $^{-1}$, com a dose de 59,4 t ha- do composto orgânico para produção de massa fresca total e a máxima produtividade de 634,3 g planta $^{-1}$ com a dose $56,1 \mathrm{t} \mathrm{ha}^{-1}$ para massa fresca da cabeça.

A dose de 26,7 $\mathrm{t} \mathrm{ha}^{-1}$ de torta de filtro na cultivar Rafaela permitiu um incremento na produção de massa fresca total de $89,98 \%$ quando comparado ao tratamento sem aplicação $\left(0 \mathrm{t} \mathrm{ha} \mathrm{h}^{-1}\right)$. Heredia et al. (1996) verificaram incrementos significativos no cultivo de alface $(54,61 \%)$ quando incorporado $14 \mathrm{t} \mathrm{ha}^{-1}$ de cama de galinha em relação ao tratamento sem aplicação. Vidigal et al. (1995) relatam que a aplicação

Tabela 1. Matéria fresca total (MFT), matéria fresca comercial (MFC) e matéria fresca da cabeça (MFCab) da alface em função da interação cultivar e dose de torta de filtro (total fresh matter (MFT), commercial fresh matter (MFC), and head fresh matter (MFCab) of crisphead lettuce depending on the interaction cultivar and filter cake rates.). Tangará da Serra, UNEMAT, 2009.

\begin{tabular}{|c|c|c|c|c|}
\hline \multirow{2}{*}{ Cultivar } & \multicolumn{4}{|c|}{ MFT (g planta ${ }^{-1}$ ) } \\
\hline & 0 t/ha & $10 \mathrm{t} / \mathrm{ha}$ & 20 t/ha & $40 \mathrm{t} / \mathrm{ha}$ \\
\hline Júlia & $333,1 \mathrm{a}$ & $439,1 \mathrm{a}$ & $372,5 b$ & $399,4 a$ \\
\hline Tainá & $278,4 a$ & $286,6 b$ & $391,2 b$ & $459,1 \mathrm{a}$ \\
\hline \multirow[t]{2}{*}{ Rafaela } & $280,6 \mathrm{a}$ & $471,9 a$ & $493,4 a$ & $477,5 \mathrm{a}$ \\
\hline & \multicolumn{4}{|c|}{ MFC (g planta $\left.{ }^{-1}\right)$} \\
\hline Júlia & $298,7 \mathrm{a}$ & $401,8 \mathrm{a}$ & $334,4 b$ & $356,5 a$ \\
\hline Tainá & $240,3 \mathrm{a}$ & $240,6 b$ & $331,8 b$ & $393,4 a$ \\
\hline \multirow[t]{2}{*}{ Rafaela } & $246,5 \mathrm{a}$ & $425,9 a$ & $451,8 \mathrm{a}$ & $433,4 \mathrm{a}$ \\
\hline & \multicolumn{4}{|c|}{ MFCab (g planta $\left.{ }^{-1}\right)$} \\
\hline Júlia & $210,9 a$ & $280,6 a$ & $229,3 b$ & $263,4 a$ \\
\hline Tainá & $178,7 \mathrm{a}$ & $174,3 b$ & $254,3 b$ & $314,6 a$ \\
\hline Rafaela & $156,5 \mathrm{a}$ & $304,6 a$ & $325,6 a$ & $307,2 \mathrm{a}$ \\
\hline
\end{tabular}

Médias seguidas pela mesma letra na coluna não diferem entre si, pelo teste Scott-Knott, $\mathrm{p}<0,05$ (means followed by the same letter in the column did not differ from each other by Scott-Knott test, $\mathrm{p}<0,05$ ); **Significativo pelo teste $\mathrm{t}, \mathrm{p}<0,01$ (significant trough $\mathrm{t}$ test, $\mathrm{p}<0,01$ ); *Significativo pelo teste $\mathrm{t}, \mathrm{p}<0,05$ (significant through $\mathrm{t}$ test, $\mathrm{p}<0,05$ ).

Tabela 2. Diâmetro da planta (DP), diâmetro do caule (DC), número de folhas totais (NFT) e número de folhas comerciais em função das cultivares de alface americana (plant diameter (DP), stem diameter (DC), total number of leaves (NFT) and number of marketable leaves (NFC) depending on crisphead lettuce cultivars). Tangará da Serra, UNEMAT, 2009.

\begin{tabular}{lcccc}
\hline Cutivar & DP $(\mathbf{c m})$ & DC $(\mathbf{c m})$ & NFT & NFC \\
\hline Júlia & $31,9 \mathrm{a}$ & $1,7 \mathrm{a}$ & $27,8 \mathrm{a}$ & $23,0 \mathrm{a}$ \\
Tainá & $29,5 \mathrm{~b}$ & $1,6 \mathrm{~b}$ & $24,1 \mathrm{~b}$ & $18,7 \mathrm{~b}$ \\
Rafaela & $31,3 \mathrm{a}$ & $1,8 \mathrm{a}$ & $28,2 \mathrm{a}$ & $23,9 \mathrm{a}$ \\
\hline
\end{tabular}

Médias seguidas pela mesma letra, em cada coluna, pertence a um mesmo grupo, de acordo com o teste de Scott-Knott, em nível de 5\% de probabilidade (averages followed by the same letter, in each column, belong to the same group, according to the Scott-Knott test, at $5 \%$ probability level).

de adubos orgânicos proporciona aumentos significativos na produtividade da alface.

A produção da cultivar Rafaela sofreu incrementos na massa fresca comercial com a aplicação de torta de filtro, atingindo a máxima produção (487,5 g) com a dose 26,66 t ha ${ }^{-1}$ (Figura 1B). Este resultado é superior ao alcançado por Silva et al. (2010), que utilizando adubação nitrogenada com diferentes compostos orgânicos, em dois ciclos sucessivos, obtiveram no primeiro ciclo, para o composto produzido a partir de esterco bovino e ipê roxo, uma produção máxima de 293,9 g planta-1 de matéria fresca da parte aérea (MFPA) com a dose de 77,8 $\mathrm{t} \mathrm{ha}^{-1}$ de composto, e para o composto esterco bovino + mistura de resíduos de unha de gato, a dose máxima calculada para MFPA foi de $86,4 \mathrm{t} \mathrm{ha}^{-1}$ de composto, com produção de 318,2 $\mathrm{g}$ planta $^{-1}$.

Neste experimento houve também interação significativa entre doses de torta de filtro e cultivares de alface americana para o comprimento do caule. A cultivar Rafaela apresentou um aumento no comprimento do caule a partir da dose $10 \mathrm{tha}^{-1}$, e atingiu o máximo comprimento de caule $(8,2 \mathrm{~cm})$ com a dose 25,19 t ha $^{-1}$ (Figura 2A). A cultivar Júlia 


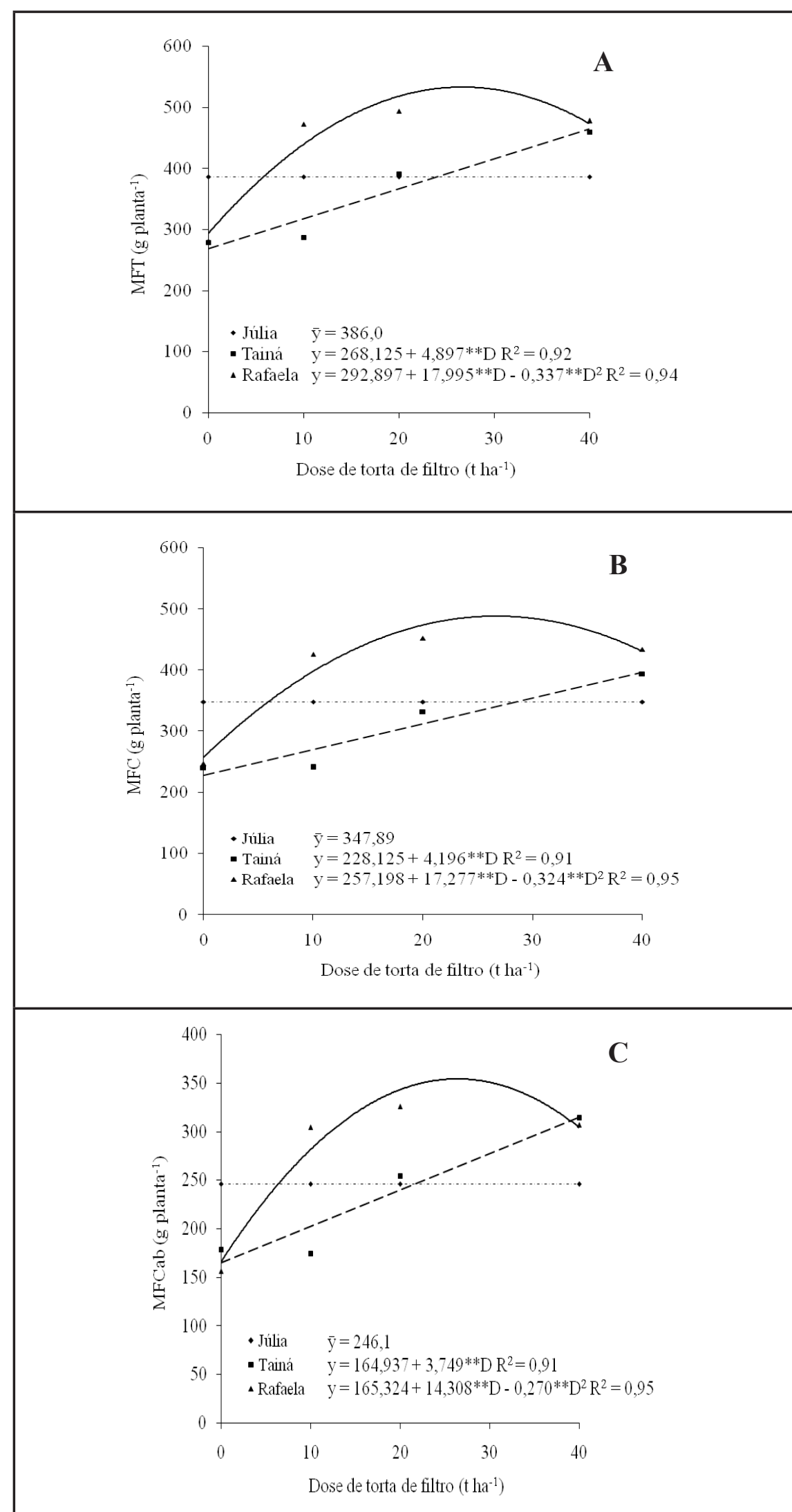

Figura 1. Equações de regressão para matéria fresca total (MFT), matéria fresca comercial (MFC) e matéria fresca da cabeça (MFCab) da alface em função da interação cultivar e dose de torta de filtro (regression equations for total fresh matter (MFT), marketable fresh matter (MFC), and head fresh matter (MFCab) of crisphead lettuce depending on the interaction cultivar and filter cake rates). Tangará da Serra, UNEMAT, 2009. apresentou o máximo comprimento de caule $(5,9 \mathrm{~cm})$ com a dose de $29 \mathrm{t}$ $\mathrm{ha}^{-1}$ e não houve aumento significativo do caule ao se aumentar as doses. A cultivar Tainá apresentou efeito linear com a aplicação de torta de filtro com um máximo em comprimento de caule $5,7 \mathrm{~cm}$ com a dose de $40 \mathrm{tha}^{-1}$ e a partir desta dose pressupõe-se um incremento no comprimento do caule conforme observa-se na Figura 2A.

Menores comprimentos de caule são desejáveis para a alface americana, principalmente quando destinada à indústria de beneficiamento, devendo ser bastante reduzido, proporcionando menores perdas durante o processamento. Por outro lado, o caule excessivamente comprido acarreta uma menor compacidade da cabeça e dificulta o beneficiamento, afetando a qualidade final do produto (Yuri et al., 2002; Resende et al., 2003). Na prática, caules com comprimento de até $6,0 \mathrm{~cm}$ seriam os mais adequados, sendo aceitáveis até o patamar de 9,0 $\mathrm{cm}$ e inaceitáveis ou menos recomendados para processamento acima disto (Resende et al., 2005).

Não houve interação entre as doses de torta de filtro e as cultivares utilizadas na presente pesquisa nas características agronômicas diâmetro da planta, diâmetro do caule, número de folhas totais e número de folhas comerciais. Aplicando-se a análise de regressão pôde-se perceber que o aumento da dose aplicada proporcionou desempenho quadrático nas características diâmetro da planta (Figura 2B) e diâmetro do caule (Figura 2B), sendo que o máximo diâmetro da planta $(32,5 \mathrm{~cm})$ foi obtido com a dose $31,51 \mathrm{t} \mathrm{ha}^{-1}$, promovendo um incremento de cerca de $12 \%$ no diâmetro da planta em relação ao tratamento em que não se aplicou torta de filtro. As cultivares Rafaela e Júlia não apresentaram diferença significativa (Tabela 2). Resultados semelhantes foram obtidos por Yuri et al. (2004) com diâmetro de planta de 41,4 $\mathrm{cm}$ com a dose 53,7 $\mathrm{tha}^{-1}$ de composto orgânico. Efeitos positivos no incremento da circunferência da planta são também relatados por Vidigal et al. (1995).

O diâmetro de caule máximo (1,9 $\mathrm{cm})$ foi obtido com a dose $32,5 \mathrm{tha}^{-1}$, (Figura 2B) e o menor diâmetro foi ob- 


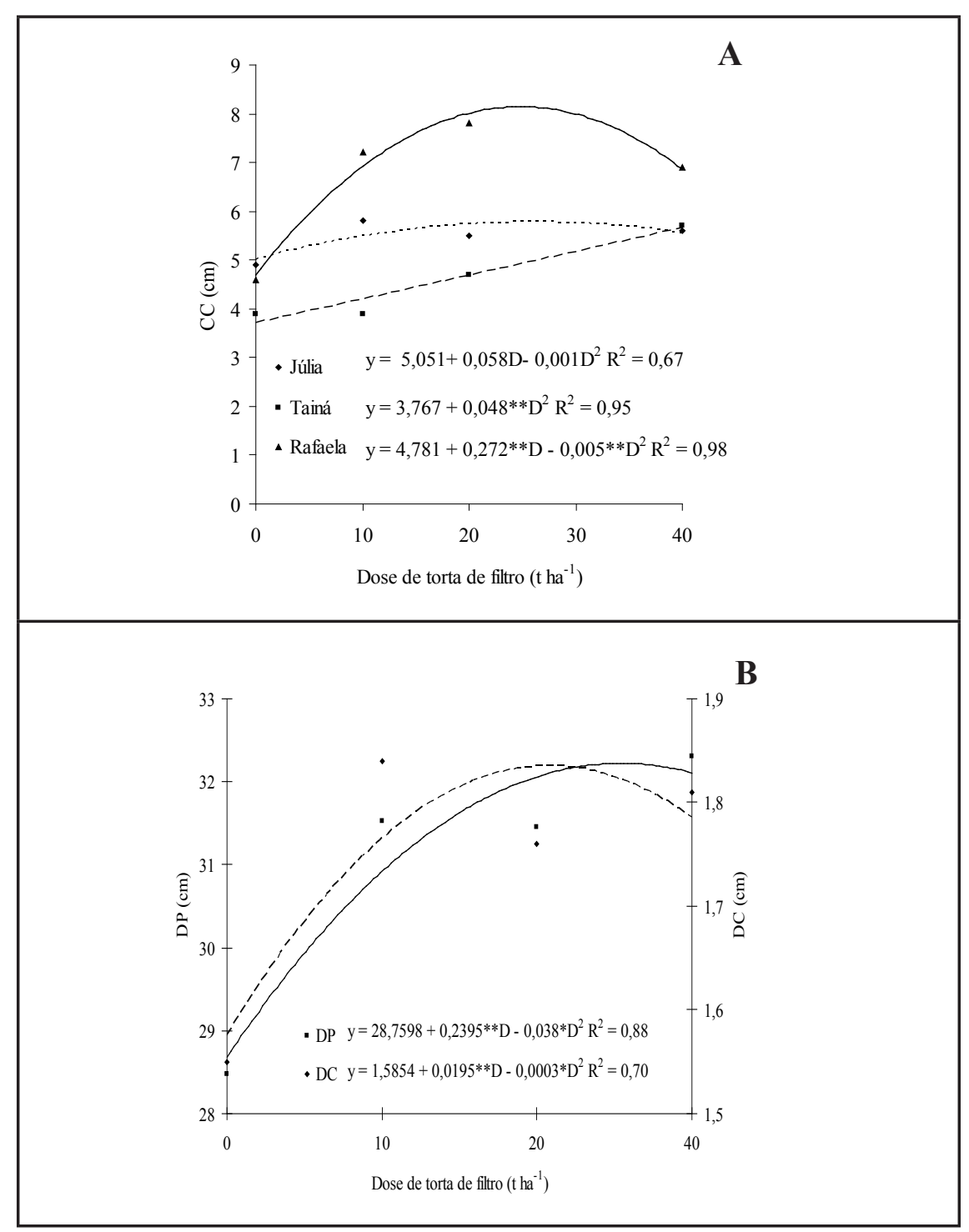

Figura 2. Comprimento do caule (CC) em função da interação cultivar e dose de torta de filtro e diâmetro da planta (DP) e diâmetro do caule (DC) de alface americana em resposta a doses de torta de filtro (stem length (CC) depending on the interaction cultivar and filter cake rates, and plant diameter (DP) and stem diameter (DC) response of crisphead lettuce to filter cake rates). Tangará da Serra, UNEMAT, 2009.

tido pela cultivar Tainá $(1,6 \mathrm{~cm})$ (Tabela 2). Vale ressaltar que a característica diâmetro do caule é de grande importância para a indústria de fast food pois, este é retirado manualmente para posterior fatiamento da cabeça da alface, quanto mais grosso é o caule mais rápido ele é retirado, aumentando o rendimento industrial (Mota, 1999).

As características agronômicas número de folhas totais e número de folhas comerciais apresentaram resultados significativos para as diferentes cultivares (Tabela 2). Para a característica número de folhas totais, não houve diferença foram observados entre as cultivares na característica número de folhas comerciais onde a cultivar Tainá foi inferior às demais com a menor média (18,7 folhas comerciais planta $\left.^{-1}\right)$. A maior média foi obtida pela cultivar Rafaela (23,9 folhas comerciais planta $\left.{ }^{-1}\right)$, não diferindo da cultivar Júlia (Tabela 2). Resultados semelhantes foram obtidos por Oliveira et al. (2009) que, avaliando diferentes adubos orgânicos e manejos de adubação verde na cultura da alface crespa cultivar Vanda obtiveram uma média de 24,6 folhas utilizando manejo adubo orgânico comercial e com o manejo mucuna-preta uma média de 21,6 folhas.

Nas condições em que foi realizado o experimento e para o tipo de composto orgânico utilizado, conclui-se que a aplicação de torta de filtro, proporcionou melhoria no rendimento e qualidade comercial da alface americana. Entre as cultivares, o destaque foi para a cultivar Rafaela.

\section{AGRADECIMENTOS}

À Fundação de Amparo à Pesquisa de Mato Grosso (FAPEMAT), pelo auxílio financeiro (proc. $\mathrm{n}^{\circ} 004.034 / 2007$ ) e Usinas Itamarati S/A.

\section{REFERÊNCIAS}

ABREU MF; ABREU JUNIOR CH; SILVA FC; SANTOS GCG; ANDRADE JC; GOMES TF; COSCIONE AR; ANDRADE CA. 2009. Análise químicas de fertilizantes orgânicos. In: SILVA FC. Manual de análises químicas de solos, plantas e fertilizantes. Brasília: Embrapa Informação Tecnológica. p. 397-488.

ARAÚJO TS; FIDELES FILHO J; KUMAR KK; RAO TVR. 2010. Crescimento da alfaceamericana em função dos ambientes, épocas e graus-dias. Revista Brasileira Ciências Agrária 5: 441-449.

ARAÚJO WF; TRAJANO EP; NETO JLR; JUNIOR MM; PEREIRA PR. 2007. Avaliação de cultivares de alface em ambiente protegido em Boa Vista, Roraima, Brasil. Acta Amazonica 37: 299-302.

BERNARDI ACC; VERRUMA-BERNADI MR; WERNECK CG; HAIM PG; MONTE MBM. 2005. Produção, aparência e teores de nitrogênio, fósforo e potássio em alface cultivada em substrato com zeólita. Horticultura Brasileira 23: 920-924.

BULLUCK LR; BROSIUS MG; EVANYLO K; RISTAINO JB. 2002. Organic and synthetic fertility amendments influence soil microbial, physical and chemical properties on organic 
and conventional farms. Applied Soil Ecology 19: $147-160$.

CASARIN V; AGUIAR IB; VITTI GC. 1989. Uso de resíduos da indústria canavieira na composição do substrato destinado à produção de mudas de Eucalyptus citriodora Hook. Cientifica 17: 63-72.

EMBRAPA - Centro Nacional de Pesquisa de Solos. 2006. Sistema brasileiro de classificação de solos. Rio de Janeiro: EMBRAPA Solos. 306p.

FERREIRA DF. 2008. SISVAR: um programa para análises e ensino de estatística. Revista Symposium 6: 36-41.

FILGUEIRA FAR. 2008. Novo manual de olericultura: agrotecnologia moderna na produção e comercialização de hortaliças. Viçosa: UFV. 421p.

FONTES PCR. 1999. Alface. In: RIBEIRO AC; GUIMARÃES PTG; ALVAREZ VVH. Recomendação para o uso de corretivos e fertilizantes em Minas Gerais: $5^{\text {a }}$ Aproximação. Viçosa: Comissão de Fertilidade do Solo do Estado de Minas Gerais. p.177.

HEREDIA ZNA; VIEIRA MC; CABEÇAS JÚNIOR O. 1996. Influência de cama de aviário semi-decomposta em cobertura e incorporada sobre a produção de alface 'Grand Rapids' em Dourados-MS. Horticultura Brasileira 14: 89-92.

INOCÊNCIO MF; PAIM LR; NOVELINO JO; NORILER AV; PEDROSO FW;
MIGLIORANÇA MVS. 2009. Características agronômicas da alface fertilizada com superfosfato triplo e ninhos de cupim. Agrarian 2: 83-93.

LIMA JD; MORAES WS; MENDONÇA JC; NOMURA ES. 2007. Resíduos da agroindústria de chá preto como substrato para produção de mudas de hortaliças. Ciência Rural 37: 1609-1613.

MOTA JH. 1999. Efeito do Cloreto de Potássio via fertirrigação na produção de alface americana em cultivo protegido. Lavras: UFLA. 46p. (Tese mestrado).

OLIVEIRA LC; STANGARLIN JR; LANA MC; SIMON D; ZIMMERMANN A. 2009. Adubação orgânica e manejo da adubação verde na cultura da alface em sistema Orgânico. Revista Brasileira de Agroecologia 4: 500-503.

PENTEADO SR. 2000. Introdução à agricultura orgânica - normas e técnicas de cultivo. Campinas: Grafimagem. 113p.

RESENDE GM; YURI JE; CARVALHO JG; SOUZA RJ; RODRIGUES JUNIOR JC; MOTA JH. 2005. Resposta da alface americana (Lactuca sativa L.) a doses e épocas de aplicação de cobre. Ciência Agrotecnologia 29: 1209-1214.

RESENDE GM; YURI JE; MOTA JH; SOUZA RJ; FREITAS SAC.; RODRIGUES JÚNIOR JC. 2003. Efeitos de tipos de bandejas e idade de transplantio de mudas sobre o desenvolvimento e produtividade de alface americana. Horticultura Brasileira 21: 562567.

RODRIGUES AB; MARTINS MIEG; ARAÚJO JCC. 1997. Avaliação econômica da produção de alface em estufa. Informações Econômicas 27: 27-33.

SCOTT AJ; KNOTT MA. 1974. A cluster analysis method for grouping means in the analysis of variance. Biometrics 30: 507-512.

SILVA FAM; VILLAS BÔAS RL; SILVA RB. 2010. Resposta da alface à adubação nitrogenada com diferentes compostos orgânicos em dois ciclos sucessivos. Acta Scientiarum. Agronomy 32: 131-137.

SOUZA JL; RESENDE PL. 2006. Manual de horticultura orgânica. Viçosa: Aprenda Fácil. 843p.

VIDIGAL MV; RIBEIRO AC; CASALI VWD; FONTES LEF. 1995. Resposta da alface (Lactuca sativa L.) ao efeito residual da adubação orgânica. I. Ensaio de campo. Revista Ceres 42: 80-88.

YURI JE; RESENDE GM; RODRIGUES JÚNIOR JC; MOTA JH; SOUZA RJ. 2004. Efeito de composto orgânico sobre a produção e características comerciais de alface americana. Horticultura Brasileira 22: 127-130.

YURI JE; SOUZA RJ; FREITAS SAC; RODRIGUES JÚNIOR JC; MOTA JH. 2002. Comportamento de cultivares de alface tipo americana em Boa Esperança. Horticultura Brasileira 20: 229-232. 